\title{
The use of 'overlapping' NOAA-AVHRR NDVI maximum value composites for Scotland and initial comparisons with the land cover census on a Scottish Regional and District basis
}

\author{
A. R. S. MARÇAL \\ Department of Applied Physics and Electronic \& Mechanical Engineering, \\ University of Dundee, Dundee DD1 4HN, Scotland, U.K. \\ and G. G. WRIGHT \\ Macaulay Land Use Research Institute, Craigiebuckler, Aberdeen AB92QJ, \\ Scotland, U.K.
}

(Received 14 May 1996; in final form 10 August 1996)

\begin{abstract}
AVHRR data from April 1995 to September 1995 have been processed to produce $1 \mathrm{~km}$ resolution NDVI Maximum Value Composites of Scotland. Temporal profiles of mean NDVI were obtained for Scottish administrative regions. Temporal NDVI profiles for individual vegetation classes, from the Land Cover of Scotland 1988 (LCS88) dataset, were obtained and both temporal and spatial variations within these classes are also discussed. A method for enhancing the existing LCS88 dataset is proposed, based on AVHRR NDVI data, by distinguishing vegetation regional variation within a single class.
\end{abstract}

\section{Introduction}

NOAA Advanced Very High Resolution Radiometer (AVHRR) has been widely used in the past for vegetation monitoring on a global and regional scale (Justice et al. 1985, Maselli et al. 1993, Derrien et al. 1992). The availability of at least one morning and one afternoon image in any 24 hour period, for a given area, makes NOAA-AVHRR data particularly appropriate to detect rapidly changing vegetation biomass change.

The Normalized Difference Vegetation Index (NDVI) is calculated from the measured radiance on the red and near-infrared part of the electromagnetic spectrum. The index is based on the fact that highly vegetated areas will have high reflectance on the near-infrared and low reflectance on the red, while water and bare soil will generally have higher reflectance on the red than on the near infrared part of the spectrum (Goward et al. 1991).

There are several factors that can cause a considerable change to the NDVI measured by satellite sensors. The most important of these factors are: changing illumination and viewing conditions within a single image and also between images of different days; the presence of cloud cover; variation in atmospheric constituents, in particular the variation in water vapour and aerosol concentrations. The use of Maximum Value Composites (MVCs) is generally accepted as an effective way of eliminating the undesirable influence of these factors (Holben 1986). The assumption behind the MVC technique is that the maximum NDVI value of a set of images will correspond to the ideal conditions: low solar zenith angle and viewing angle, low 
concentration of water vapour and aerosols and cloud-free conditions. This assumption is true for a NDVI MVC produced from a large number of images (which will depend on the geographical location and atmospheric conditions). However, a large number of images per MVC will correspond to long compositing periods and the loss of meaningful vegetation biomass change. It is therefore important to achieve a compromise between consistency and frequency of multi-temporal NDVI MVC data.

In areas such as Scotland, where the presence of cloud cover is frequent even during the Spring and Summer, it is difficult to obtain sufficient cloud free images during one year using satellites with a long repetition period such as Landsat or Spot. Legg (1988) studied the frequency of Landsat MSS cloud-free images for Scotland between 1976 and 1986. He showed that the average number of clear Landsat views per year was between 2 and 6, and very dependent on the location. These values suggest that it is not possible to monitor the vegetation biomass change of Scotland with Landsat data alone. Although AVHRR data have a much lower spatial resolution than Landsat data, AVHRR can provide daily images from which it is possible to obtain a reasonable number of cloud free images and therefore provide enough data to monitor the vegetation biomass change of Scotland on a national or regional scale.

The Land Cover of Scotland 88 Survey (LCS88) treats land cover classes, such as arable agriculture, improved pasture or smooth grassland uniformly throughout the country. However, as the growth of these cover features is affected by climate, there should be substantial differences in their vegetation dynamics within Scotland. Using AVHRR derived NDVI MVC data it should be possible to evaluate regional differences in vegetation biomass change and as a result enhance or add value to the existing LCS88 dataset.

\section{The LCS88 dataset}

\subsection{Background}

The Land Cover of Scotland 1988 (LCS88) (MLURI 1993 a) survey is the first ever national census of land cover in Scotland. It was produced to assist in developing and monitoring the effectiveness of future countryside policies, following increasing concern about the nature and rate of land use change in Scotland. Readers interested in obtaining more information about the project, technical aspects and comprehensive information on the validation and general statistics, are referred to the main project report (MLURI 1993 b).

The project was conducted in three main phases. The first phase involved obtaining medium scale (1:24000), monochrome aerial photography for the whole of Scotland, a decision based on a through review of various land cover initiatives in the United Kingdom (Coppock and Kirby 1987). This was achieved over three flying seasons, from 1987 to 1989, most of it (35 per cent) during the week 6-12 June 1988. The second phase required the interpretation of this photography to extract land cover information, and subsequently the conversion of this information into a computer-readable dataset. The final phase was a ground validation exercise of the data.

\subsection{Land cover classification}

There is not a standard land cover classification system in the United Kingdom, although the need for a common classification framework is well recognised (Wyatt et al. 1993). The classification used in the LCS 88 recognises the sponsors requirements 
to have information on rural, and in particular semi-natural, land cover in Scotland. The hierarchical classification system adopted recognised principal, major and main land cover features, with various sub-categories. For example, semi-natural ground vegetation (principal feature) may comprise heather and dwarf shrub heathland (major features), which can be further sub-divided into dry heather moor (main feature), which may or may not have muirburn, rock outcrops or scattered trees (sub-categories). An important feature of the classification, is that it allows for mosaics (mixtures of cover features, where patch sizes are below minimum mapping areas) of the single land cover features to be identified.

The description of the five land cover features used in this work are presented below; the full list of individual and mosaic features can be found in the LCS88 Final Report (MLURI 1993 b).

1. Improved Pasture. Improved pastures have species of grass and clover of high palatability and grazing value and are generally established by cultivation or reseeding and maintained by grazing control and use of lime and fertilisers. These latter measures can, if followed over a period of time, achieve effects on semi-natural grassland similar to those of reseeding.

2. Heather Moor. Areas dominated by heather species (particularly Calluna vulgaris). In this study they are intermediate in character between dry and wet heather moors and have a variable mixture of coarse grasses. They are of a considerably poorer grazing quality than the improved pastures.

3. Smooth Grass. Undifferentiated smooth grasslands include principally areas with bent-fescue grassland communities on brown forest soils and podzols, on hill slopes or rugged terrain. They are nearer in grazing quality to improved pastures than heather moors.

4. Montane Vegetation. Land above the treeline, represented on soil maps as carrying alpine or subalpine soils, often carrying mountain grassland and herb species or dwarf varieties of heather moorland vegetation.

5. Golf Courses. Golf courses in the countryside away from, or contiguous with but not within, built up areas.

For this study, a $500 \mathrm{~m}$ ground resolution (pixel) dataset was used, with classes being assigned to the predominant individual feature from the original raster $(50 \mathrm{~m})$ LCS 88 dataset. Scottish administrative Regions and Districts (in operation at the time of this study) were used to evaluate, nationally, the spatial variations in vegetation condition. Figure 1 shows the Scottish Regions (the Shetland Islands were not included) and the Districts used in this work.

\section{AVHRR data processing}

NOAA AVHRR data were collected for Scotland between April 1995 and September 1995. During that period two NOAA satellites were operational (NOAA-12 and NOAA-14). However, as NOAA-12 (0730 LST descending node) morning orbits have very low illumination angles, its data are unreliable for vegetation assessment, only NOAA-14 afternoon orbit (1340 LST ascending node) data were used (Kidwell 1995). Images with a high percentage of cloud cover, or with a very oblique view, were rejected as the NDVI values tend to be less reliable and it is difficult to achieve high accuracy in the rectification process. 


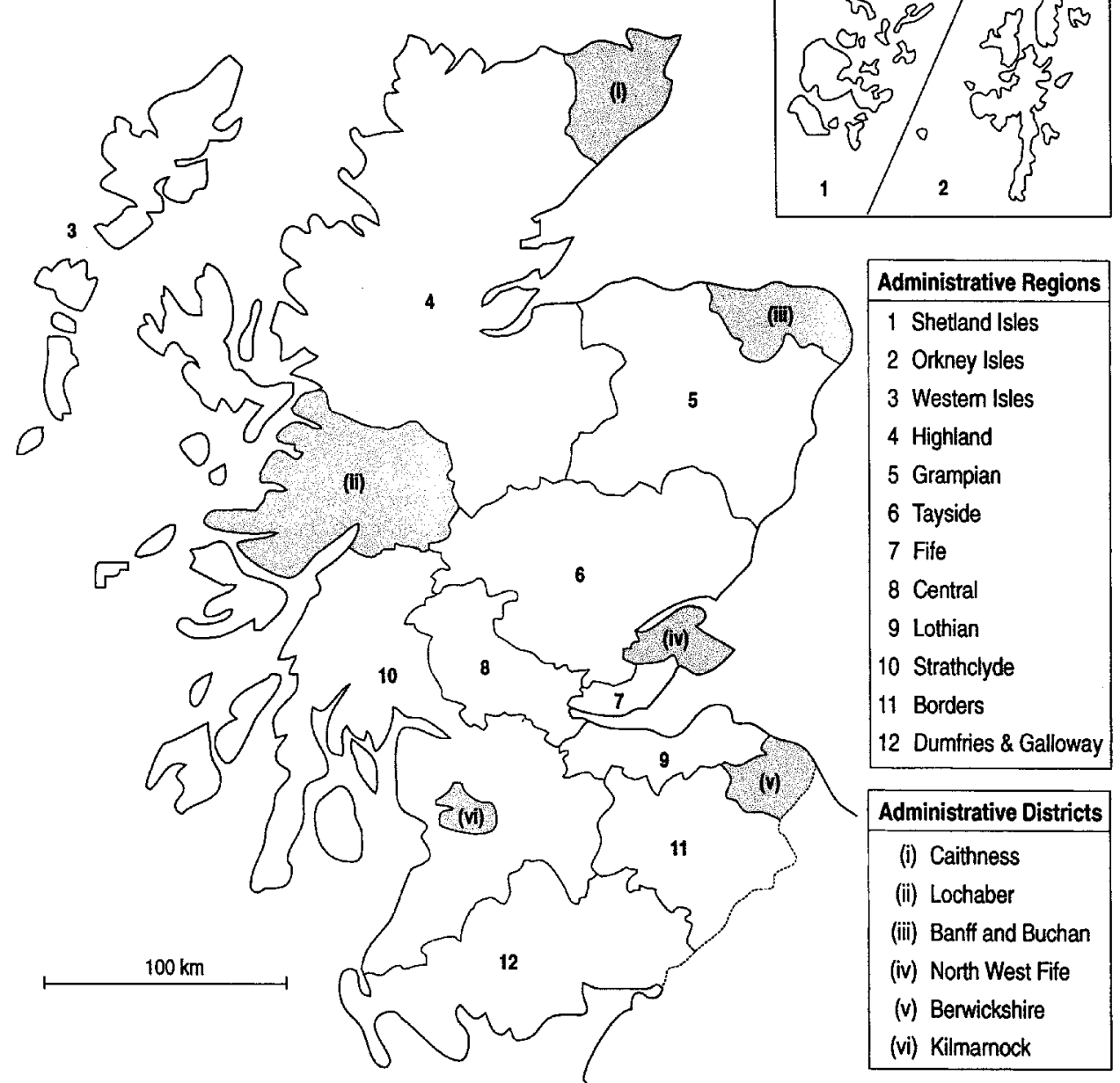

Figure 1. Former Scottish administrative regions and selected districts used in this study.

\subsection{Pre-processing}

The Normalized Difference Vegetation Index (NDVI) was calculated from the measured radiance on AVHRR channels $1\left(L_{\text {red }}\right)$ and $2\left(L_{\text {nir }}\right)$ using equation $(1)$. The radiance measured by each channel was calculated using the pre-launch calibration parameters provided by NOAA (Kidwell 1995). As NOAA-14 has only been operational since 30 December 1994, the sensor decay is not thought to be substantial and therefore the pre-launch calibration coefficients were used. The NDVI values were multiplied by a factor of 1000 and stored in 16 bit format.

$$
\mathrm{NDVI}=\max \left\{0, \frac{L_{n i r}-L_{r e d}}{L_{n i r}+L_{r e d}}\right\}
$$

Ground Control Points (GCP) were inserted on each AVHRR image by identifying similar features (such as water features or coastlines) on the raw satellite image and on a digital map of Scotland. The distinctive coastline of Scotland made it 
generally possible, the exception being the presence of clouds, to insert about 50 well spread GCPs on each raw satellite image of 500 pixels by 500 lines. Great care was taken in this process as it is important to rectify an image as accurately as possible for the purpose of temporal analysis. GCPs with high root mean square (rms) residual errors were double-checked and none of the GCPs used had a rms residual error higher than 0.35 of a pixel. Each raw satellite image was then subject to a third order polynomial transformation with cubic convolution resampling into a dataset with $1 \mathrm{~km}$ pixel size (Emery et al. 1989). A dataset with $500 \mathrm{~m}$ pixel size was also produced to match the LCS 88 data.

\subsection{Independent ND VI maximum value composites}

The NOAA satellites repetition cycle is approximately nine days, and within a repetition cycle there are three or four images of a given location which do not have high viewing angles (above 20-25 degrees). Assuming an ideal situation of absence of clouds, between nine and thirteen images would be available to produce a monthly NDVI MVC. However, as some of those 9-13 images will be predominantly cloudy, the number of images available for georeferencing and compositing will generally be smaller. We can assume that consistent monthly NDVI MVCs can be produced if at least five or six of those possible 9-13 images are predominantly cloud-free in every month being studied.

Monthly NDVI Maximum Value Composites (MVCs) were produced for May, June, July and August 1995, although the number of images available for May was only four. There were five images available for each month for June, July and August. NDVI MVCs were produced for April and September, although only a small number of images were available for these months (two and three respectively). The resulting NDVI MVCs produced, however, could not be consistently compared with those produced for May-August, and were therefore not included in this part of the study.

\subsection{Overlapping NDVI maximum value composites}

To be able to analyse continuous vegetation biomass change in Scotland from early Spring to the end of Summer, another approach has to be used. Instead of using a fixed compositing period for each NDVI MVC, regardless of the number of images available on that period, independent NDVI MVCs from a fixed number of images were produced. The compositing periods will vary depending on the availability of data which are conditioned by atmospheric conditions and by the satellite repetition period. By producing intermediate NDVI MVCs (overlapping), it is possible to obtain smoother temporal profiles and increased temporal resolution. The correlation between successive MVCs is closely related with the amount of overlap, as the differences between consecutive MVCs decrease with increasing overlap.

MVCs were produced from six images and the overlap between consecutive MVCs was four images. A total of ten NDVI MVCs were produced, four independent and six overlapping, from the 24 AVHRR images available (table 1). Figure 2 shows a temporal plot of the mean NDVI MVC of Fife administrative region, calculated using monthly composites (void dots) and six images per MVC (full dots). A description of the images used for each NDVI MVC, the period, the Julian day (abscissa for the NDVI temporal graphics), and the number of days between consecutive MVCs is presented on table 1 .

The use of fewer images per MVC would have shortened the compositing periods 
Table 1. Description of the NDVI Maximum Value Composites used. Each NDVI MVC was produced from six AVHRR images. There is an overlap of four AVHRR images between consecutive composites.

\begin{tabular}{llccc}
\hline $\begin{array}{l}\text { MVC } \\
\text { No. }\end{array}$ & \multicolumn{1}{c}{ Images used } & $\begin{array}{c}\text { MVC size } \\
\text { (No. days) }\end{array}$ & $\begin{array}{c}\text { Julian day of } \\
\text { MVC }\end{array}$ & $\begin{array}{c}\text { No. days from } \\
\text { previous MVC }\end{array}$ \\
\hline 1 & 12, 13 April, 1, 3, 17, 20 May & 38 & 121 & \\
2 & 1, 3, 17, 20 May, 12, 15 June & 45 & 142 & 21 \\
3 & 17,20 May, 12, 15, 24, 25 June & 39 & 159 & 17 \\
4 & 12, 15, 24, 25, 26 June, 8 July & 26 & 174 & 15 \\
5 & 24, 25, 26 June, 8, 22, 25 July & 31 & 188 & 14 \\
6 & 26 June, 8, 22, 25, 27, 30 July & 34 & 199 & 11 \\
7 & 22, 25, 27, 30 July, 1, 4, August & 13 & 209 & 10 \\
8 & 27, 30 July, 1, 4, 9, 10 August & 14 & 215 & 6 \\
9 & 1, 4, 9, 10, 20 August, 14 September & 44 & 227 & 12 \\
10 & $9,10,20$ August, 14, 26, 28 September & 50 & 245 & 18 \\
\hline
\end{tabular}

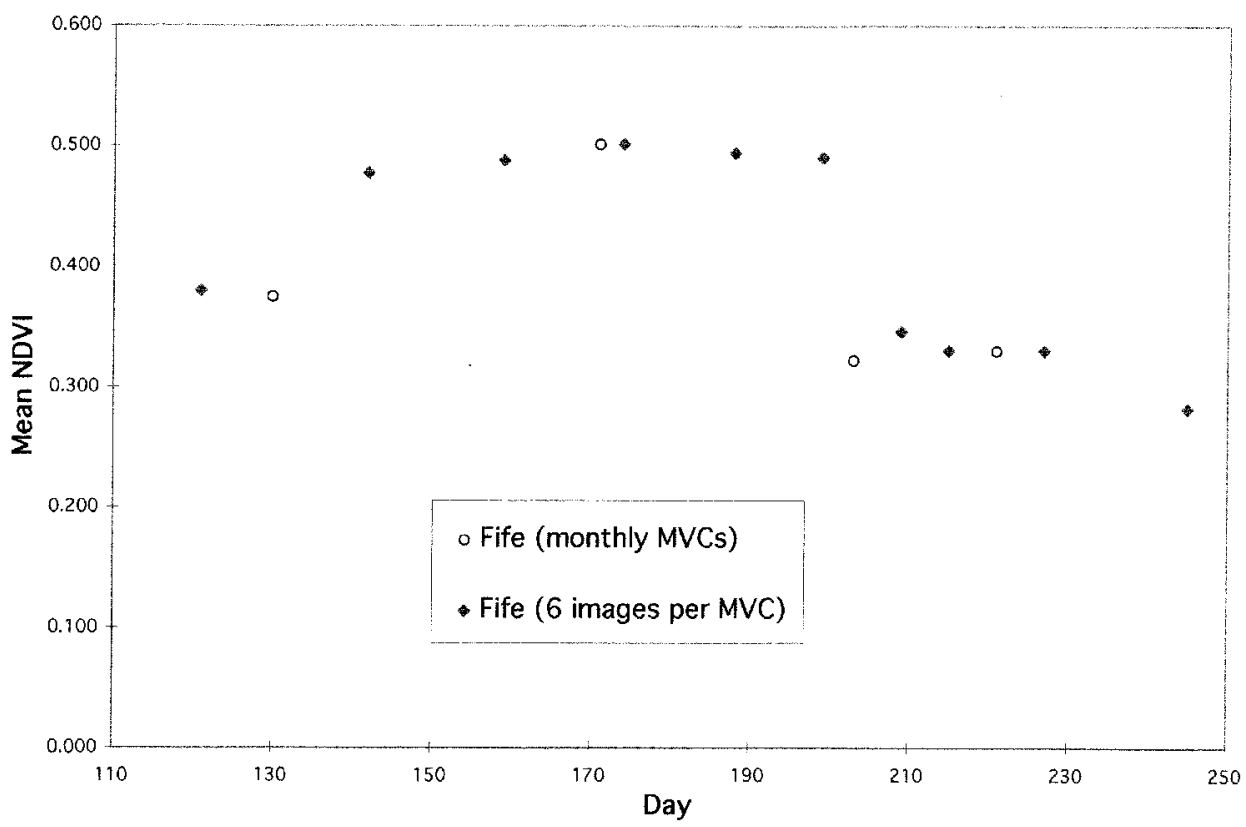

Figure 2. Temporal plot of mean NDVI for Fife region, from monthly MVCs and from overlapping MVCs with 6 AVHRR images each.

and given greater sensitivity to vegetative dynamics. However, it would also have increased the impact of the other factors. The use of six images is a compromise between these conflicting effects.

\section{Results}

The mean NDVI values of each former Scottish administrative region for each of the 10 NDVI MVC periods (table 1) were plotted (figure 3). The NDVI values are generally higher in the Southern regions than in the North. The NDVI temporal plots of Fife and Lothian, which are essentially arable agriculture regions, are clearly 


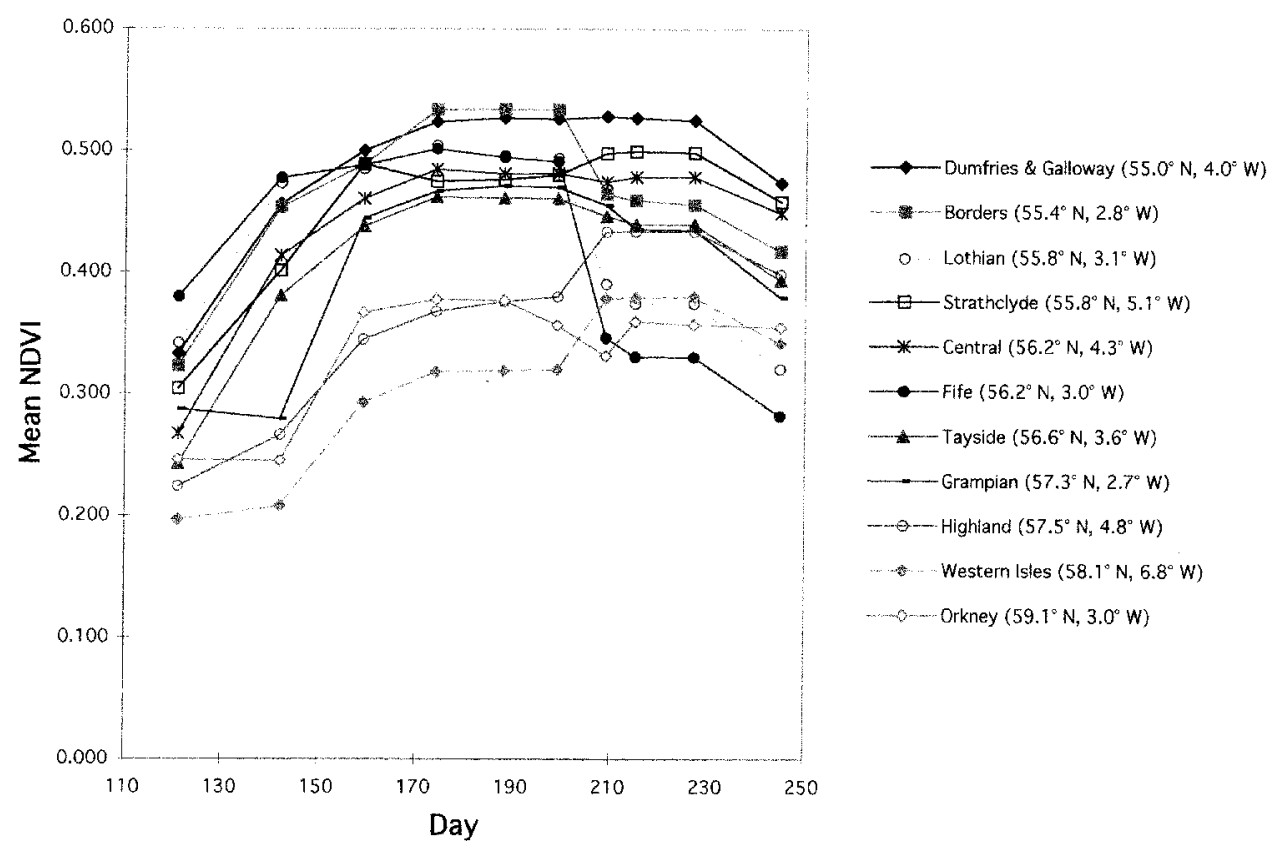

Figure 3. Mean NDVI temporal profile of Scottish administrative regions from 1 May (121st day) to 2 September 1995 (245th day). The NDVI values were obtained by maximum value compositing six AVHRR images.

distinguished from those of other regions. A steep decrease in NDVI in mid July, corresponding to crop harvest, is most pronounced in these two regions. It is also noticeable that for Grampian and Orkney, both of which have a considerable agricultural component, there is a delay in the increase of NDVI values at the start of the growing season, in comparison with the other Scottish regions. The later start to the growing season in the Northern regions is almost certainly due to the colder conditions prevailing during early Spring. The authors recognise, however, that this delay may simply be an artefact of the overlapping MVCs. In Highland and Western Isles, where the land cover is predominantly semi-natural vegetation, the NDVI values develop slowly but steadily throughout Spring and Summer, decreasing slightly in September.

For the five representative LCS88 classes selected (Improved Pasture, Heather Moor, Smooth Grass, Montane Vegetation and Golf Courses), temporal plots of mean NDVI MVC were produced (figure 4). Only Golf Courses had a small number of pixels. The measured NDVI for Montane Vegetation and Heather Moor shows growth from the beginning of May (Julian day 121) until late August (Julian day 243) and then a very slight decrease in September. This decrease might be due to lower illumination angles rather than to vegetation itself. The NDVI for Improved Pasture and Smooth Grass shows substantial growth in May and beginning of June, followed by a steady period of about four weeks for Improved Pasture and about seven weeks for Smooth Grass. The NDVI values decrease during the rest of the Summer with a more intense decrease on the Improved Pasture class, which during 1995 was under stress due to drought conditions. The NDVI plot of Golf Courses is very similar in 


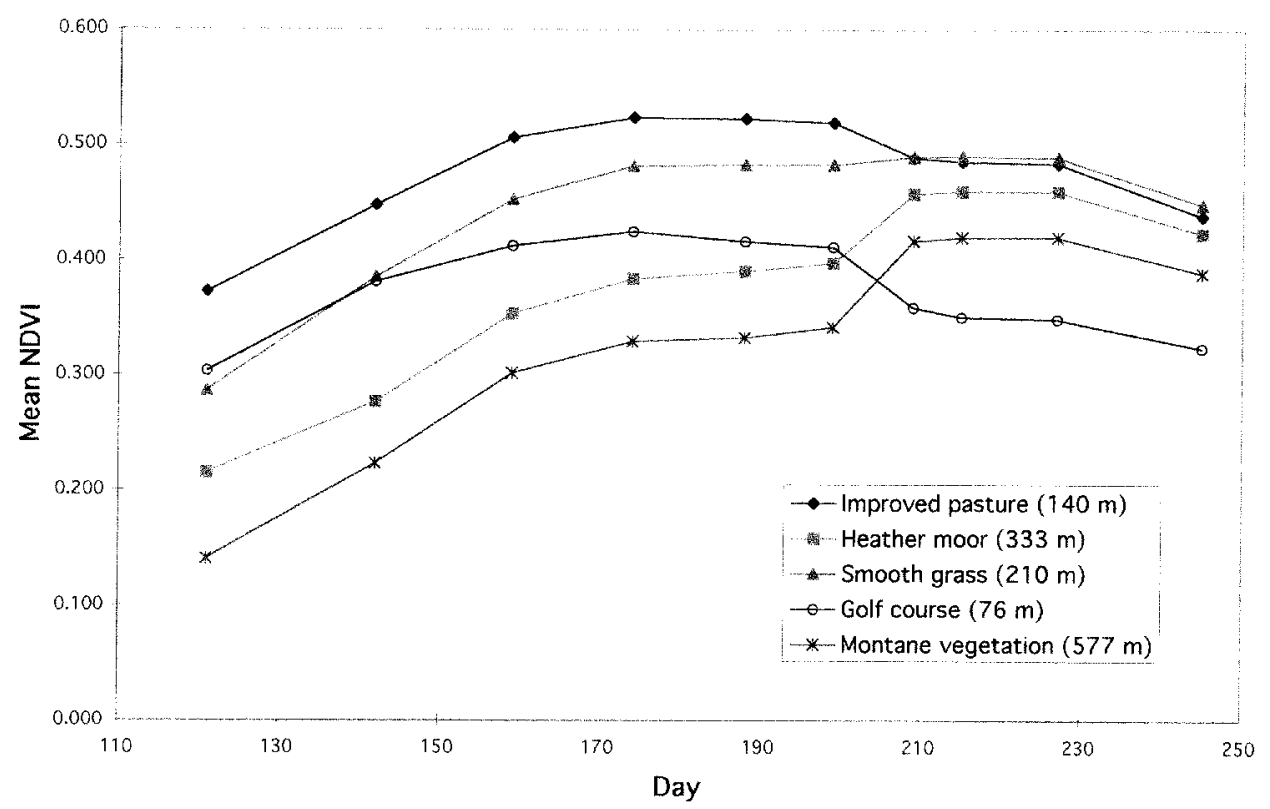

Figure 4. Mean NDVI temporal profile of Scotland, on selected LCS88 classes, from 1 May (121st day) to 2 September 1995 (245th day). () Mean altitude of the land cover class.

shape to that of Improved Pasture, with NDVI values 15-25 per cent lower, as the drought induced growth stress was more severe over these features.

The graphics on figure 4, as discussed above, were produced by averaging the NDVI of pixels from a cover class for all of Scotland. However, the spectral response of a given type of vegetation is not expected to be the same from different climatic and geographical locations. The regional variation within a single LCS88 class was analysed by plotting the temporal NDVI profiles of five regions of Scotland, for Improved Pasture (figure 5), Smooth Grass (figure 6), and Heather Moor (figure 7). The same pattern found for mean regional values is observed for specific classes. South and east regions tend to have higher values than north and west regions. Also, the Spring increase in NDVI values for grass and pasture is later for northern regions than it is for southern ones.

Figure 8 shows the temporal plots of mean NDVI MVC values for six administrative districts of Scotland (sub-sections of the administrative regions). These districts were selected because of their high percentage of land use for some of the LCS 88 classes. The district percentages of dominant land cover classes is presented on table 2. The three eastern districts, Banff and Buchan, North East Fife and Berwickshire, are predominantly arable agriculture. The NDVI temporal profiles in these districts are generally similar, apart from a later NDVI increase in the growing season in Banff and Buchan (the further north of three districts), and a different amount of NDVI decrease in the crop harvest. This difference could be explained with information about the dominant crop and the state at harvest. The NDVI temporal profiles of Caithness and Lochaber, where the predominant land cover classes are Peat Vegetation and Heather Moor, are very similar. The higher NDVI values in Caithness in the Spring and lower in late Summer can be justified by the higher percentage in Improved Pasture in this district. The Kilmarnock district has a different mean NDVI 


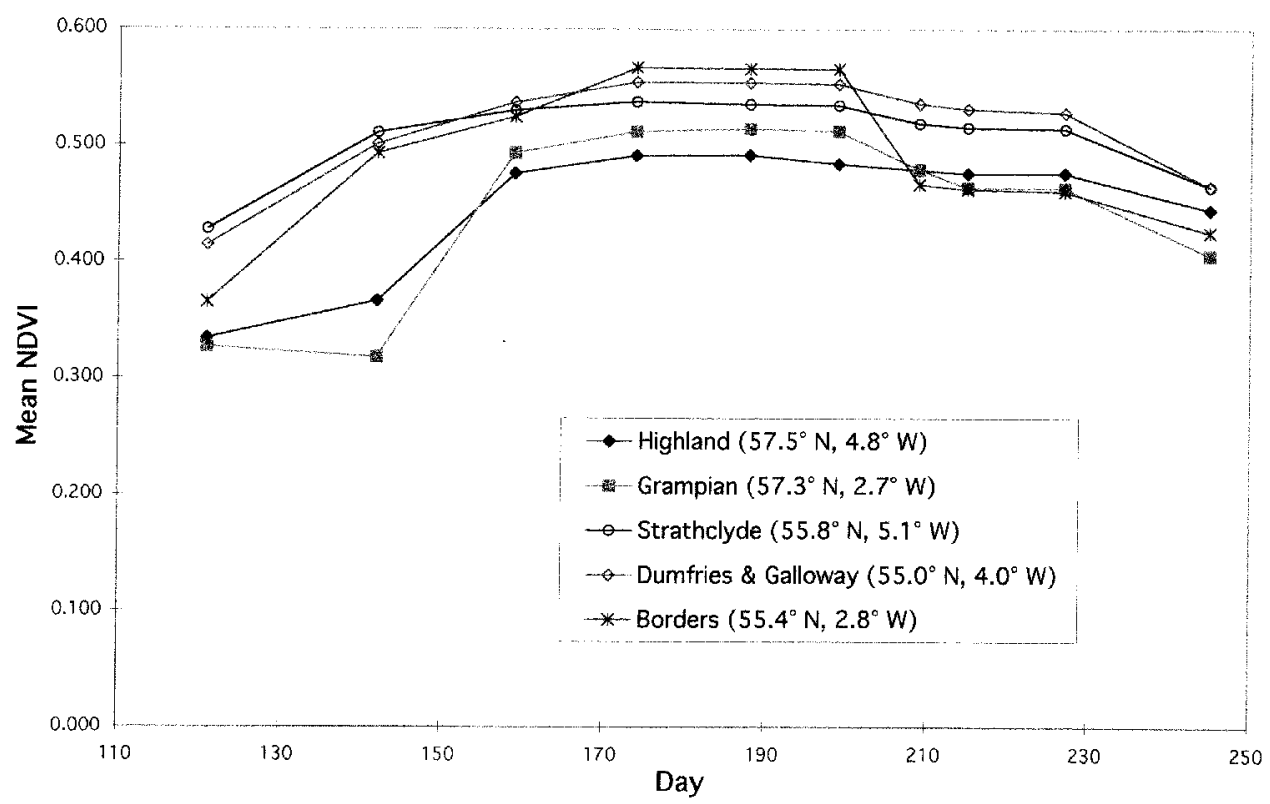

Figure 5. Mean NDVI temporal profile of Improved Pasture LCS88 class, for the five most representative regions, from 1 May (121st day) to 2 September 1995 (245th day).

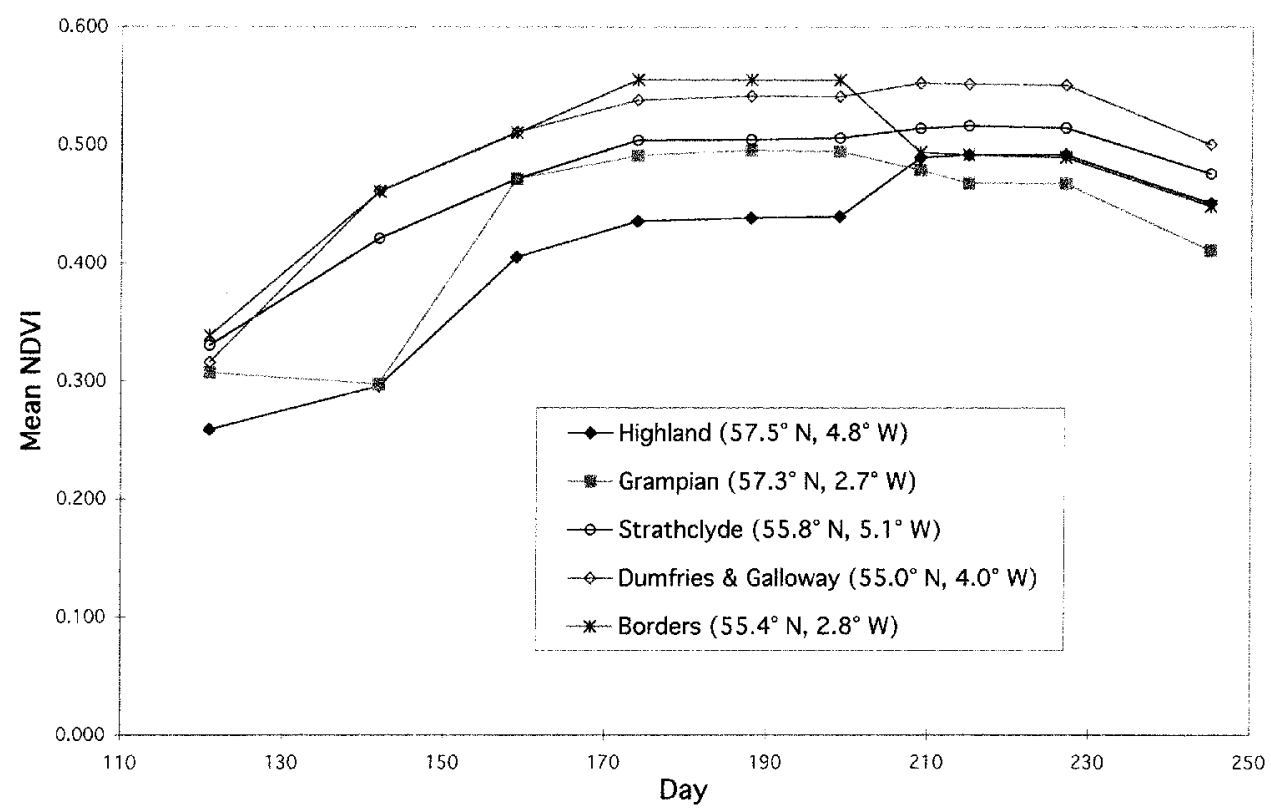

Figure 6. Mean NDVI temporal profile of Smooth Grass LCS88 class, for the five most representative regions, from 1 May (121st day) to 2 September 1995 (245th day).

MVC profile. The most dominant class in this district is Improved Pasture and, as a consequence, the mean NDVI MVC plot for this district is very similar to that of Improved Pasture in the Strathclyde region (figure 5). 


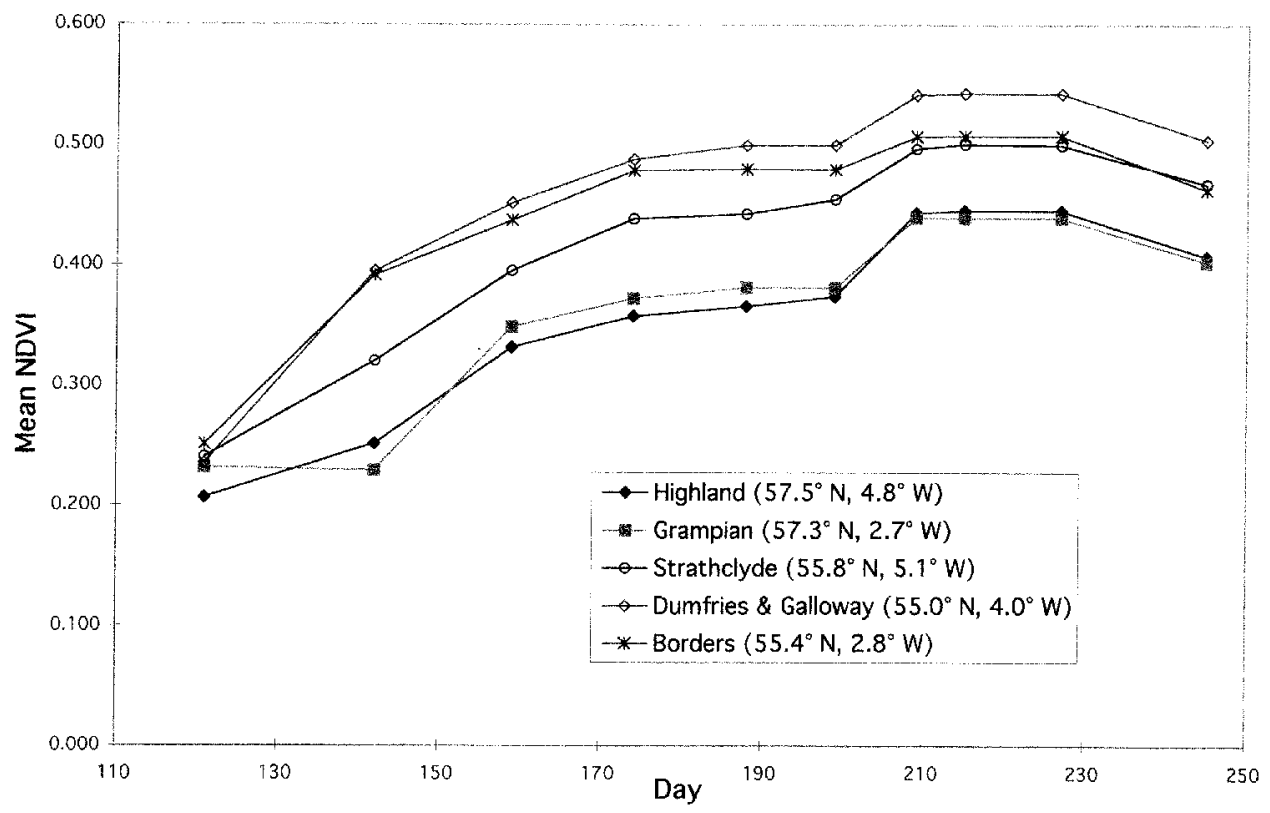

Figure 7. Mean NDVI temporal profile of Heather Moor LCS88 class, for the five most representative regions, from 1 May (121st day) to 2 September 1995 (245th day).

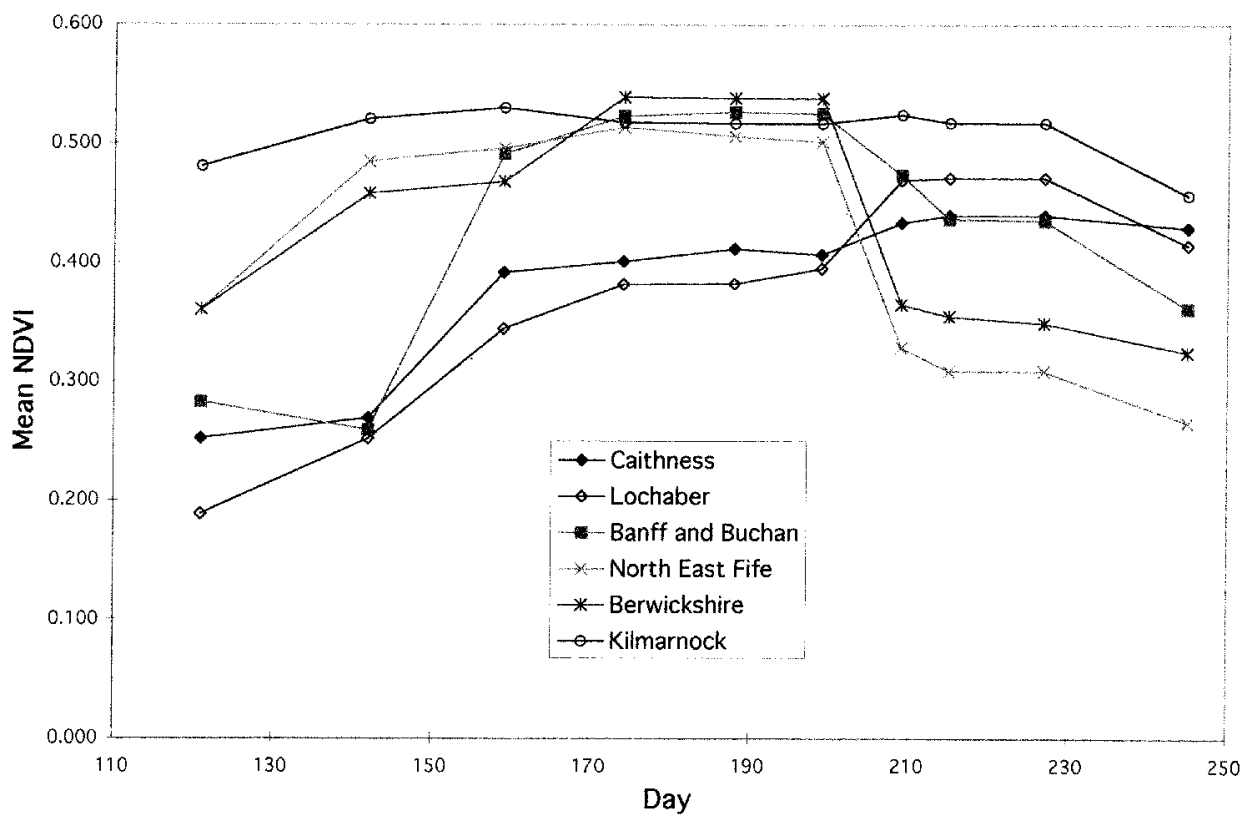

Figure 8. Mean NDVI temporal profile of six Scottish administrative districts from 1 May (121st day) to 2 September 1995 (245th day). 


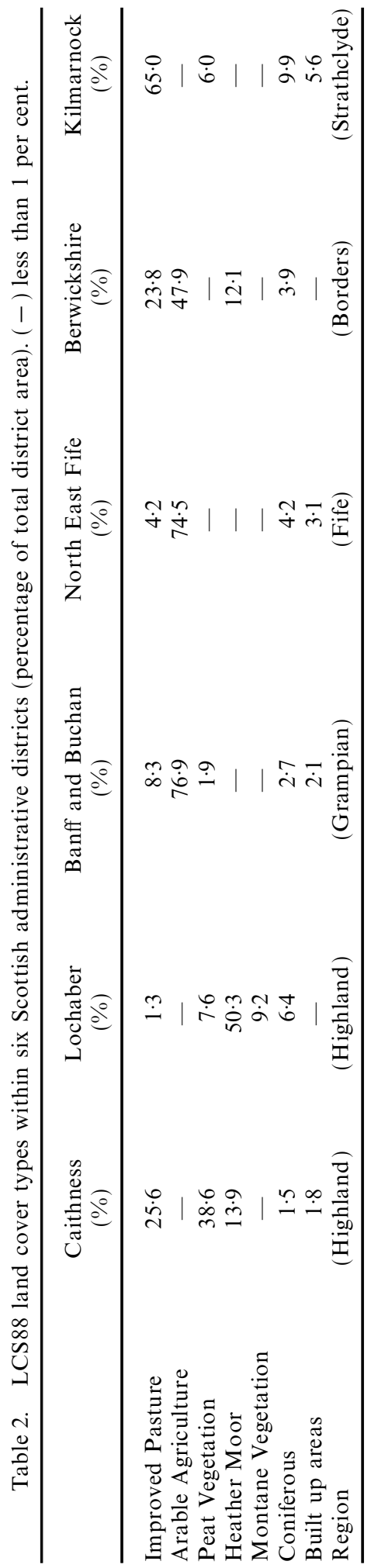




\section{Discussion}

The NDVI temporal profiles produced for each Scottish region and for selected districts and LCS88 cover types showed clear differences between regions and district as a whole and within a single land cover type.

The spatial resolution of the NDVI MVC dataset, $1 \mathrm{~km}$, is a limiting factor in the analysis of vegetation of different cover types. The LCS88 dataset used here was produced from the original $(50 \mathrm{~m})$ by aggregation into $500 \mathrm{~m}$ pixels. This aggregation is by majority, which means that a pixel may only have 50 per cent of its area with its assigned class. A percentage model was used, with $1000 \mathrm{~m}$ pixels and five classes (Arable Agriculture, Pasture, Semi-Natural Vegetation, Urban Areas, Water), to assess the effect of mixed classes on the overall mean NDVI. The percentage model was tested in the period between April and September 95. The mean NDVI for pixels with at least 70 per cent of Semi Natural Vegetation did not vary more than 4 per cent from the mean NDVI calculated from pixels with 90 per cent or more Semi Natural Vegetation. The same test was done for Arable Agriculture with a result of less than 2 per cent variation. These values suggest that the overall effect of mixed land cover pixels is not too important, at least for the most frequent classes. Classes with a reduced number of pixels are more subject to errors on the mean NDVI due to mixed land cover pixels. To be able to analyse these classes accurately, it would be necessary to produce a land cover percentage model for each individual class, which involves considerable computation time and resources. Although we were aware of the small variations by using the aggregation model, it was thought that for this regional study, the straightforward aggregation ( 50 per cent + class dominance) was adequate.

To obtain meaningful NDVI temporal profiles, it is necessary that the NDVI MVCs are consistent. To achieve consistency between NDVI MVCs, the calibration of AVHRR raw data and, most importantly, the rectification stage, have all to be carefully performed. An error of one or two pixels in the rectification of one image can significantly change the NDVI MVC, specially in areas with high variation of NDVI values. It is also important to be aware of some other limiting factors in addition to the availability of cloud-free images with near-nadir satellite view. In high latitudes such as Scotland, early Spring and late Summer satellite data have the restriction of high solar zenith angles. By simulation studies (Singh 1988), it was shown that the measured NDVI values of vegetated areas remain constant with solar zenith angles up to about $30^{\circ}$, and that for larger solar zenith angles, the NDVI values decrease smoothly and significantly. The decrease in NDVI on vegetated areas reached, on this simulation, 33 per cent for a solar zenith angle of 70 . Calculations on selected sites in Scotland showed that all the images used from May to August had solar zenith angles between 33 and 50 degrees. However, the two images from April had values of solar zenith angle above 50 degrees, reaching 62 degrees in the far North of Scotland on the 28 of September. These values and the results of Singh simulation suggest that the measured NDVI for the April and September images have an important decrease due to low solar illumination, and that the period studied, April to September, is probably the maximum range possible for Scotland.

\section{Conclusion}

The advantages of using overlapping NDVI MVCs in areas where the availability of quality data is limited is clearly demonstrated. It has been shown that there are spatial variations in the temporal NDVI profiles within the major LCS88 cover types. This comes as no surprise given that vegetation condition is related to geographic and climatic location as well as altitude. The AVHRR derived NDVI data 
can be used to provide a more objective regional analysis of the major cover features identified in the LCS88 survey.

One of the future possible applications would be the use of overlapping temporal NDVI MVC profiles as an input to vegetation resource management, such as a grazing management model (Sibbald et al. 1987). At present, the successful use of this type of model is dependent on historical, coarse resolution, derived climatic information. The NDVI MVCs would provide the potential for near real time input and thus a more objective analysis of regional climate variation and biomass production.

\section{Acknowledgments}

The authors wish to acknowledge the NERC Dundee Satellite Station for providing AVHRR data and JNICT (Junta Nacional de Investigação Científica e Tecnológica) for the financial support. The research was also undertaken within the remote sensing and GIS programme at MLURI, funded by the Scottish Office, Agriculture Environment and Fisheries Department. Special thanks must also be given to A. R. Sibbald at MLURI for his considerable assistance and knowledge during many stages of this study.

\section{References}

Coppock, J. T., and KIRBY, R. P., 1987, Review of approaches and sources for monitoring change in the landscape of Scotland. Consultancy Report for the Scottish Development Department, Scottish Office, Edinburgh.

Derrien, M., Farki, B., Legleau, H., and Sairouni, A., 1992, Vegetation cover mapping over France using NOAA-11/AVHRR. International Journal of Remote Sensing, 13, $1787-1795$.

EMERY, W. J., Brown, J., and NowAK, Z., 1989, AVHRR image navigation: summary and review. Photogrammetric Engineering and Remote Sensing, 55, 1175-1183.

Goward, S. N., Markham, B., Dye, D. G., Dulaney, W., and Yang, J., 1991, Normalized difference vegetation index measurements from the advanced very high resolution radiometer. Remote Sensing of Environment, 35, 257-277.

Holben, B., 1986, Characteristics of maximum-value composite images from temporal AVHRR data. International Journal of Remote Sensing, 7, 1417-1434.

Justice, C. O., Townshend, J. R. G., Holben, B. N., and Tucker, C. J., 1985, Analysis of the phenology of global vegetation using meteorological satellite data. International Journal of Remote Sensing, 6, 1271-1318.

KIDwell, K. B., 1995, NOAA Polar Orbiter Data Users Guide, National Oceanic and Atmospheric Administration National Environmental Satellite Data and Information Service.

LEGG, C. A., 1988, Acquisition of Landsat MSS imagery of the UK, 1976-1986, NRSC.

Maselli, F., Conese, C., Petkov, L., and Gilabert, M. A., 1993, Environmental monitoring and crop forecasting in the Sahel through the use of NOAA NDVI data. A case study: Niger 1986-89. International Journal of Remote Sensing, 14, 3471-3487.

MLURI, 1993 a, The Land Cover of Scotland 1988, Executive Summary, Macaulay Land Use Research Institute, Aberdeen.

MLURI, 1993 b, The Land Cover of Scotland 1988, Final Report, Macaulay Land Use Research Institute, Aberdeen.

SINGH, S. M., 1988, Simulation of solar zenith angle effect on global vegetation index (GVI) data. International Journal of Remote Sensing, 9, 237-248.

Sibbald, A. R., Grant, S. A., Milne, J. A., and Maxwell, T. J., 1987, Heather moorland management-a model. Agriculture and Conservation in the Hills and Uplands, edited by M. Bell and R. G. H. Bunce (Grange over Sands: Institute of Terrestrial Ecology), pp. 107-108.

W yatt, B. K., Greatorex Davies, N., Bruce, R. G. H., and Hill, M. O., 1993, Comparison of land cover definitions. Final report. ITE Monks Wood. 